DISTRIBUTION STATEMENT A. Approved for public release; distribution is unlimited.

\title{
A Non-Fickian Mixing Model for Stratified Turbulent Flows
}

\author{
Tamay M. Özgökmen \\ Division of Meteorology and Physical Oceanography \\ Rosenstiel School of Marine and Atmospheric Science \\ 4600 Rickenbacker Causeway \\ Miami, Florida 33149 \\ phone: 305421 4053, fax: 305421 4696, email: tozgokmen@rsmas.miami.edu \\ Award \#: N00014-09-1-0267 \\ http://www.rsmas.miami.edu/personal/tamay/3D/mli.html/ \\ The long term goal of this project is to develop a better understanding of oceanic processes in the \\ range of $100 \mathrm{~m}$ to $10 \mathrm{~km}$, in the so-called submesoscale range. In particular, it is important to \\ explore and find out whether and what type of submesoscale instabilities exist, how they are \\ connected to both larger scale and smaller scale motions, and to what extent they influence \\ transport processes in the ocean. Another important objective of this project is to test how well \\ subgrid-scale (SGS) models for large eddy simulations (LES) work in the presence of backward \\ energy cascade that may be characteristic in submesoscale motions. A long term objective of this \\ effort would be to improve the predictive skill of the Navy numerical models for submesoscale
}

\section{LONG-TERM GOALS} transport in the ocean.

\section{OBJECTIVES}

My main objective has been to model upper ocean mixed layer instabilities, investigate their behavior and try to develop sampling strategies using synthetic drifters and tracers prior to the first LatMix cruises. In addition, modeling help with data analysis is planned.

\section{APPROACH}

The work is based on LES using the non-hydrostatic spectral element model Nek5000 as well as field data. Also, software has been developed in order to automatically download and make available MODIS raw SST data over the selected region in the first LatMix cruise.

\section{WORK COMPLETED}

I have completed work on eight papers (see Publications section) under the support of the LatMix project. Of these, two (Özgökmen et al., 2011; Özgökmen and Fischer, 2012) contain a detailed analysis of mixed layer instability (MLI) with particular emphasis on sampling strategies using LES. Two papers focus on subgrid-scale models, in LES (Berselli et al., 2011) and in ocean models (Marques and Özgökmen, 2012). Our approach in Özgökmen et al. (2012) is perhaps the first truly multi-scale LES aiming to dissect the interaction between the submesoscale MLI and deep mesoscale baroclinic instability, and how their multi-scale signature 


\section{Report Documentation Page}

Form Approved

OMB No. 0704-0188

Public reporting burden for the collection of information is estimated to average 1 hour per response, including the time for reviewing instructions, searching existing data sources, gathering and maintaining the data needed, and completing and reviewing the collection of information. Send comments regarding this burden estimate or any other aspect of this collection of information,

including suggestions for reducing this burden, to Washington Headquarters Services, Directorate for Information Operations and Reports, 1215 Jefferson Davis Highway, Suite 1204, Arlington

VA 22202-4302. Respondents should be aware that notwithstanding any other provision of law, no person shall be subject to a penalty for failing to comply with a collection of information if it

does not display a currently valid OMB control number.

1. REPORT DATE

30 SEP 2012

4. TITLE AND SUBTITLE

A Non-Fickian Mixing Model for Stratified Turbulent Flows

6. $\operatorname{AUTHOR}(\mathrm{S})$

7. PERFORMING ORGANIZATION NAME(S) AND ADDRESS(ES)

University of Miami,Rosenstiel School of Marine and Atmoshperic Science,4600 Rickenbacker Causeway,Miami,FL,33149

9. SPONSORING/MONITORING AGENCY NAME(S) AND ADDRESS(ES)

12. DISTRIBUTION/AVAILABILITY STATEMENT

Approved for public release; distribution unlimited

13. SUPPLEMENTARY NOTES

14. ABSTRACT

15. SUBJECT TERMS

16. SECURITY CLASSIFICATION OF:

a. REPORT

unclassified b. ABSTRACT

unclassified c. THIS PAGE

unclassified
17. LIMITATION OF ABSTRACT

Same as

Report (SAR)
3. DATES COVERED

00-00-2012 to 00-00-2012

5a. CONTRACT NUMBER

5b. GRANT NUMBER

5c. PROGRAM ELEMENT NUMBER

5d. PROJECT NUMBER

5e. TASK NUMBER

5f. WORK UNIT NUMBER

8. PERFORMING ORGANIZATION

REPORT NUMBER

10. SPONSOR/MONITOR'S ACRONYM(S)

11. SPONSOR/MONITOR'S REPORT

NUMBER(S) 
can be detected on the basis of scale-dependent relative dispersion plots. I also investigated the observation periods needed for the effects of submesoscale and mesoscale-induced dispersion to show up in these plots. The study by Mensa et al. (2012) is on the seasonality of submesoscale features in the Gulf Stream from realistic, multiple resolution HYCOM simulations, and how a combination of MLI and frontogenesis act to form these features. In Schroeder et al (2012), we summarize results from a targeted drifter launch at a coastal frontal zone. In Haza et al. (2012), we evaluate two different classes of subgrid-scale parameterizations for Lagrangian dispersion in HYCOM for the North Atlantic in order to compensate for the effect of enhanced dispersion over submesoscale regime that is typically missing in mesoscale eddy resolving models.

\section{RESULTS}

A subset of results are presented below, one from a computational LES study and another from a field experiment on lateral mixing. I have presented a number of new computations during the LatMix meeting in June 2012, which have not been prepared for publication, and therefore, not included below.

\section{1) Deduction of submesoscale and mesoscale interactions from dispersion:}

This study is motivated by a recent observation of the emergence of submesoscale features along the rim of a cyclonic Gulf Stream ring that was noted during the 2011 Summer LatMix cruise (Fig. 1). These submesoscale features developed within days after a cyclonic (cold core) ring entrained warm water from the Gulf Stream, but apparently completely dissipated within three weeks of their emergence. Submesoscale features have been notoriously difficult to observe in situ, while remote sensing instruments provide occasional glimpses into their structure and rapid evolution. The implication of the multi-scale interaction in this particular case is that submesoscale flows appear sporadically because special circumstances are needed for their formation, and dissipate quickly under the action of mesoscale stirring.

During the time period when both the mesoscale eddy and submesoscale features coexist, the question arises as to which scales control transport. The primary objective of this study is to investigate the validity of two contrasting hypotheses: Hypothesis-I where mesoscale eddies exert non-local control over small scale transport and Hypothesis-II where dispersion and transport at the submesoscales is governed by eddying motions at local scales. The implication of Hypothesis-I is that mesoscale eddy-resolving data-assimilating (current generation) OGCMs would provide adequate predictions in applied important problems such as transport of coastal pollutants and oil spills, while Hypothesis-II would indicate that OGCMs would significantly underestimate the dispersion of a passive pollutant until the patch size grows to the scale of the local radius of deformation. Another complementary objective of this study is to provide insight into the question of whether and how instabilities below the mixed layer influence surface transport.

LES is used to assess transport properties of multi-scale ocean flows. In particular, the initial density perturbation field is specified in a way that MLI eddies are approximately an order of magnitude smaller than deeper eddies. A parallel experiment is configured for comparison in which the stratification below the mixed layer has no available potential energy, and thereby no independent turbulent coherent structures from the surface motion can form. 
In particular, we compare scale-dependent measures of Lagrangian relative dispersion and the evolution of passive tracer releases in numerical experiments containing only submesoscale MLI, and MLI modified by deeper, baroclinic mesoscale disturbances.

Visualization of turbulent coherent structures through 3D finite-time Lyapunov exponents (FTLEs) and analysis of surface kinetic energy wave-number spectra show that smaller scale instabilities in the mixed layer rapidly lose their coherence in the presence of larger scale straining induced by mesoscale motions (Fig. 2). Tracer-based eddy diffusivity computed to quantify the turbulent exchange across the mixed layer front yields approximately $0.25 \mathrm{~m}^{2} / \mathrm{s}$ uniformly within the mixed layer depth in the case of MLI only, but the frontal turbulent exchange diffusivity increases to $5 \mathrm{~m}^{2} / \mathrm{s}$ as the flow transitions to mesoscales (Fig. 3, upper panel). This result is likely to be related to shallow mixed layer depths representative of summer conditions in the North Atlantic. Winter mixed layers are typically an order of magnitude deeper, possibly creating large enough mixed layer eddies that can survive the larger scale straining for long periods.

The scale-dependent FSLE $\lambda(\delta)$ curves for both cases are computed by releasing 7803 synthetic Lagrangian particles within a $5 \mathrm{~km}$ by $5 \mathrm{~km}$ square over the front at three levels within the mixed layer. The numerical experiment in which only the MLI is present leads to results consistent with Hypothesis-II, namely a single FSLE plateau emerges at separation scales smaller than the MLI eddies. Given the small length-scales and energy of the MLI eddies, however, the inverse cascade produces a relatively weak mesoscale flow over the limited time period examined. The separation times increase approximately linearly with separation scale for all scales greater than approximately $300 \mathrm{~m}$.

The primary new advance made by this study is that during the period when both MLI and deeper instabilities are present, $\lambda(\delta)$ at 0 and $10 \mathrm{~m}$ depths show two distinct plateau clearly associated with the disparate instability scales (Fig. 3, lower panel). There is a complete collapse of these curves with the one calculated from particle releases at $25 \mathrm{~m}$ for separation distances larger than the scale of MLI eddies $(\delta>1000 \mathrm{~m})$, indicating that larger scale motions are controlled by deep instabilities. While we do not directly compare flows with and without submesoscale features, the strong effect of such small-scale features on surface transport can be inferred from the significant differences in the dispersion characteristics observed above and below the mixed layer depth in Exp II.

These results indicate the distinct possibility of Hypothesis-II holding, at least episodically, in the upper ocean. For computational reasons, we have examined a situation with two disparate length scales imposed. One could, however, easily imagine multiple mixed layer fronts driven by a range of lateral buoyancy gradients forming eddies of various scales with their mutual interaction creating a nearly continuous spectrum of submesoscale features. We have put forward parameterizations to compensate for the dispersion defect between Hypothesis-I and HypothesisII for the submesoscales in OGCMs have been put forward recently (Haza et al., 2012).

Given that simultaneous release thousands of drifters is currently not feasible in oceanic experiments, but numbers on the order of one hundred can be readily considered in dedicated studies, the sensitivity of $\lambda(\delta)$ is explored to the number of drifters and duration of the trajectories so that both plateau can be captured. The results indicate that the submesoscale plateau emerges readily with even 32 drifters, while timing and duration are important 
considerations to reveal both plateau. Timing is important in that submesoscales do not coexist with mesoscales perpetually while the drifters must sample the flow field long enough to separate under slower evolving mesoscale motions. The results imply that a field experiment would require fast sampling drifters (on the order of minutes) and at least one-month long trajectories to span the scale separation.

\section{2) Targeted sampling of submesoscale dispersion at a coastal frontal zone:}

Relative dispersion at oceanic submesoscales is still largely unknown, and has been experimentally investigated so far mostly in the open ocean and for scales greater than $1 \mathrm{~km}$ (LaCasce and Ohlmann, 2003; Koszalka et al., 2009, Lumpkin et al., 2010, Schroeder et al., 2011, Berti et al., 2011). With collaborators in Italy and France, we have conducted two experiments in the summer of 2010, which directly target relative dispersion induced by a persistent coastal front in the submesoscale range of $100 \mathrm{~m}$ to $1000 \mathrm{~m}$. A novel sampling strategy has been used to provide insight into the quantification of initial tracer dispersion under submesoscale motions.

The area of interest is the Eastern Ligurian Sea (in the North-Western Mediterranean Sea, Fig. 4 upper right). The region is characterized by depths shallower than $200 \mathrm{~m}$ and is influenced by the Arno river discharge along with some minor rivers, creating favorable conditions for the formation of buoyancy fronts within the coastal area. The Eastern Ligurian Sea is dynamically different from the central and deeper part of the Ligurian basin, which is characterized by a strong and coherent cyclonic circulation (the Liguro-Provencal current), with a typical deformation radius of $10 \mathrm{~km}$ or more. Relative dispersion in the Liguro-Provencal current was previously studied within the framework of two field experiments (Marine Rapid Environmental Assessment, MREA07/08), where drifters were released in clusters with a separation distance of $1 \mathrm{~km}$ (Schroeder et al., 2011). MREA07/08 results showed the presence of a non-local dispersion regime for the submesocale range of 1 to $10 \mathrm{~km}$.

The two experiments reported here took place in the Eastern Ligurian Sea during the summer of 2010 and were conducted by an extensive international partnership. The Ligurian Dispersion Experiment (hereafter LIDEX10) was led by the Italian Consiglio Nazionale delle Ricerche during July 2010 with the RV Maria Grazia, while the Recognized Environmental Picture 2010 experiment (hereafter REP10) was led by the NATO Undersea Research Center with the NRV Alliance during August-September 2010. During both experiments, drifter deployment locations were selected with the help of satellite images, especially the chlorophyll concentration (Fig. 4, lower left) to identify the frontal area separating rich/turbid coastal waters from the offshore waters. In the case of LIDEX10, in situ salinity data were collected by performing CTD casts every 0.5 to $1 \mathrm{~km}$ across the front (from the surface to a depth of $50 \mathrm{~m}$ ), while a Scanfish, a towed undulating vehicle, was used to precisely delineate the front during REP10 (Fig. 4, lower right).

The data set used to compute relative dispersion, the primary metric of interest, derive from CODE drifters deployed with a multi-scale approach. The deployment kernel consisted of clusters of nine drifters, composed of three triplets, initially separated by distances ranging between $50 \mathrm{~m}$ and $600 \mathrm{~m}$. This strategy was chosen to assure that a sufficiently high number of pairs at different separation distances would be available for the computation of dispersion metrics. Nineteen drifters were launched during LIDEX10 and eleven drifters during REP10. 
To support the interpretation of the ongoing dynamics, the ocean model ROMS was employed to simulate the Ligurian Sea circulation during the LIDEX10 and REP10 trials. The horizontal resolution of this model is $1.7 \mathrm{~km}$, with 32 vertical sigma-coordinate levels (see Fig. 4 for the Ligurian Sea ROMS domain). The model was initialized in May 2010 with the Mediterranean Forecasting System (MFS) model analysis. Open boundary conditions, provided by MFS, were applied to tracers and baroclinic velocity with radiation and nudging, while free surface and depth-integrated velocity boundary conditions were applied following. The high-resolution, nonhydrostatic, atmospheric model COSMO-ME of the Italian Air Force National Meteorological Center (Centro Nazionale per la Meteorologia e Climatologia Aeronautica) provided the surface forcing. Three major rivers are included as lateral boundary conditions: Arno, Serchio and Magra (monthly climatologies). No data assimilation was employed.

To study the dispersion regimes from the ocean model, synthetic drifters were released in the model, following two strategies: (a) Synthetic drifters are launched corresponding to the actual time and location of real deployments LIDEX10 and REP10. (b) In order to ensure statistical reliability of the results, large ensembles of synthetic trajectories are also used for both LIDEX10 and REP10 experiments. The ensembles consisted of 135 particles launched 11 times at 12 hours intervals around the time of actual in-situ drifter deployments. The spatial distribution of each launch consisted of 29 grid points centered around the in-situ drifter launching points, with a cross-configuration corresponding to 1 center particle at each grid point and 4 satellite ones, displaced by $500 \mathrm{~m}$ along the four cardinal directions. Drifter trajectories were integrated on-line in 2D at $0.5 \mathrm{~m}$ depth in order to mimic the response of the real drifters, and trajectories sampled at 30 minute intervals are used to compute relative dispersion statistics.

The scale dependent FSLE highlights relative dispersion over the submesoscales. Results from LIDEX10 and REP10 are presented in Fig. 5 and clearly demonstrate a dispersion regime that is scale-dependent (local) at all separation scales. Results from both LIDEX10 and REP10 data are consistent with one another. MREA07/08 results ranging down to $\delta \approx 100 \mathrm{~m}$ are also shown, on the basis of chance pairs. The contrast with respect to MREA07/08 is quite significant over the submesoscales in that there is a persistent increase in the FSLE with a Richardson's power law of $\lambda \sim \delta^{-2 / 3}$ over the submesoscales $(\delta<10 \mathrm{~km})$ ending up with a limiting value of $\lambda_{\max } \approx 20$ days $^{-1}$ at the smallest separations of $\delta<100 \mathrm{~m}$ attained during LIDEX10 and REP10. This value of the limiting FSLE is about an order of magnitude greater than that obtained in the Ligurian Sea circulation during MREA07/08. ROMS simulations clearly lack any dispersive turbulent motions below the mesoscale separations of $\delta \leq 10 \mathrm{~km}$. There is however very good agreement between results from launches with strategy-(a) and strategy-(b) for LIDEX10 over the submesoscales (same for REP10, not shown). Note that all curves converge over the mesoscale regime of $\delta>10 \mathrm{~km}$ and show ballistic scaling $\lambda \sim \delta^{-1}$, associated with horizontal shear zones created by gyres and boundary currents in the Ligurian Sea.

It is concluded that tightly-spaced clusters of drifters constitute an efficient and inexpensive observational technique to obtain relative dispersion statistics from rapidly-evolving submesoscale flows with minimal aliasing. It is found on the basis of both relative dispersion and and scale-dependent FSLE that time scales of $\mathrm{t}<15$ hours and space scales of $\delta<1 \mathrm{~km}$, that are characteristic of submesoscale phenomena, exhibit enhanced relative dispersion compared to larger scales of motion. In particular, values were obtained reaching $\lambda \approx 20$ days $^{-1}$ for $\delta<100$ $\mathrm{m}$, which is an order of magnitude greater than those obtained for the off-shore mesoscale flows. 
Computations with realistically-configured $1.7 \mathrm{~km}$ horizontal resolution ROMS were unable to capture this enhanced dispersion regime, indicating the need for subgrid-scale models for submesoscale transport.

\section{IMPACT/APPLICATIONS}

The scales considered in this project represent the range of scale of navy operations and thus anomalous currents and perturbations in the acoustic and optical environment that can affect a variety of navy operations. Understanding the motion in this range of scales is therefore critical to help improve the predictive capability of the existing Navy models.

\section{REFERENCES}

Berti, S., Santos, F.A.D., Lacorata, G., Vulpiani, A., 2011: Lagrangian drifter dispersion in the Southwestern Atlantic Ocean. J. Phys. Oceanogr. 41, 1659-1672.

Koszalka, I., LaCasce, J.H., Orvik, K.A., 2009: Relative dispersion statistics in the Nordic Seas. J. Mar. Res. 67, 411-433.

LaCasce, J.H. and C. Ohlmann, 2003: Relatve dispersion at the surface of the Gulf of Mexico. J. Mar. Res., 58, 863-894.

Lumpkin, R., Elipot, S., 2010: Surface drifter pair spreading in the North Atlantic. J. Geophys. Res. Oceans 115, C12017.

Schroeder, K., Haza, A.C., Griffa, A., Özgökmen, T.M., Poulain, P., Gerin, R., Peggion, G., Rixen, M., 2011: Relative dispersion in the Liguro-Provencal basin: from sub-mesoscale to mesoscale. Deep Sea Res. I 58, 861-882.

\section{PUBLICATIONS}

Özgökmen, T.M, P.F. Fischer, A.C. Poje and A.C. Haza, 2011: Large eddy simulations of mixed layer instabilities and sampling strategies. Ocean Modelling, 39, 311-331 [published, refereed].

Berselli, L.C., P.F. Fischer, T. Iliescu and T.M. Özgökmen, 2011: Horizontal approximate deconvolution for stratifed flows: analysis and computations. J. Sci. Comput., 49, 3-20. [published, refereed].

Haza, A.C., T.M. Özgökmen, A. Griffa, Z.D. Garraffo and L. Piterbarg, 2012: Parameterization of particle transport at submesoscales in the Gulf Stream region using Lagrangian subgridscale models. Ocean Modelling, 42, 31-49 [published, refereed].

Özgökmen, T.M. and P.F. Fischer, 2012: CFD application to oceanic mixed layer sampling with Lagrangian platforms. Int. J. Comp. Fluid Dyn. doi: 10.1080/10618562.2012.668888. [in press, refereed].

Schroeder K., Chiggiato, J., Haza, A.C., A. Griffa, Özgökmen, T.M., P. Zanasca, A. Molcard, M. Borghini, P.M. Poulain, R. Gerin, Z. Zambianchi, P. Falco and C. Trees, 2012: Targeted 
Lagrangian sampling of submesoscale dispersion at a coastal frontal zone. Geophys. Res. Lett., 39, L11608, doi:10.1029/2012GL051879 [published, refereed].

Özgökmen, T.M., A.C. Poje, P.F. Fischer, H. Childs, H. Krishnan, C. Garth, A. Haza and E. Ryan, 2012: On multi-scale dispersion under the influence of surface mixed layer instabilities and deep flows. Ocean Modelling, 56, 16-30 [published, refereed].

Marques, G.M. and T.M. Özgökmen: On modeling the turbulent exchange in buoyancy-driven fronts. Ocean Modelling [submitted, refereed].

Mensa, J. A. Griffa, Z. Garraffo, T.M. . Özgökmen and M. Veneziani: Seasonality of the submesoscale dynamics in the Gulf Stream region. Ocean Dynamics, in preparation. 

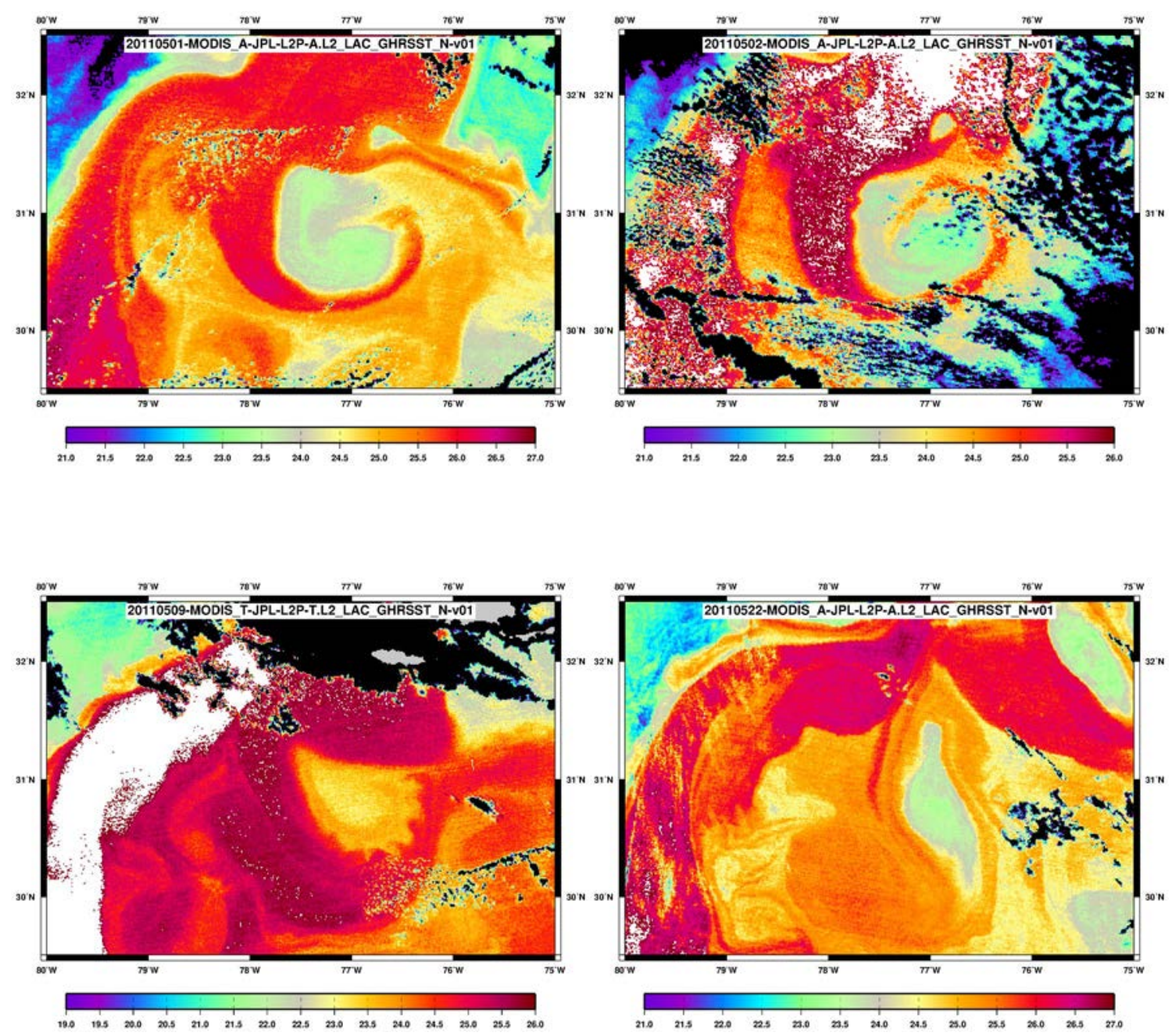

Fig. 1: An example of submesoscale instabilities from MODIS SST images in the Gulf Stream region during the 2011 Summer LATMIX cruise. (Upper left) Entrainment of $a$ warm filament around a cyclonic eddy, $t=0$ (May 1, 2011). (Upper right) The onset what appears to be mixed layer instabilities at $t=1$ day. (Lower left) Formation of sinusoidal perturbations along the rim of the cyclonic eddy at $t=2$ days. (Lower right) The state of the eddy at $t=22$ days. 

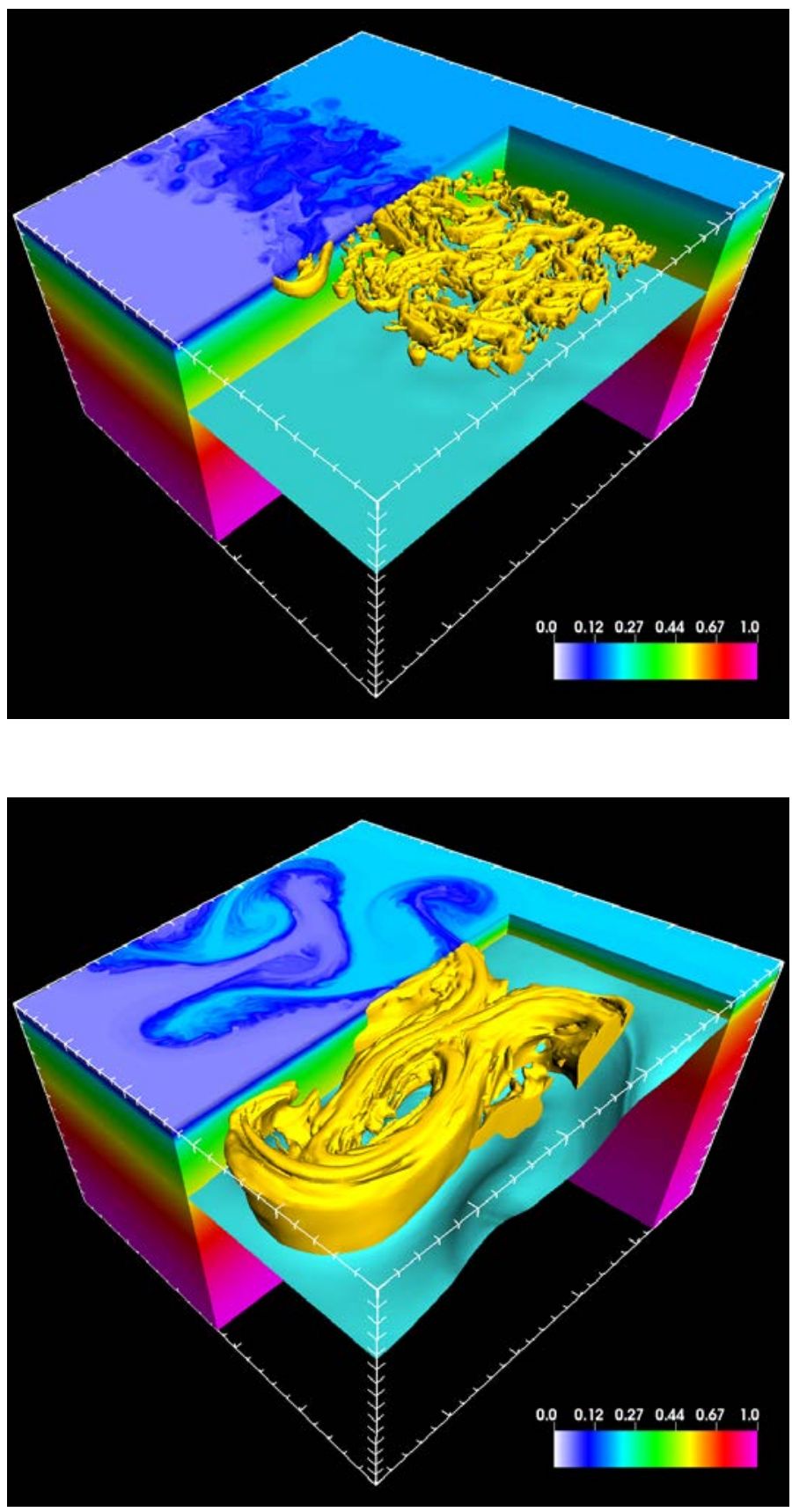

Fig. 2: Density perturbation fields from LES and 3D FTLEs (yellow) in the case of MLI only (upper panel) and when also deep baroclinic instability is also present (lower panel). Note the disappearance of MLI after deep baroclinic eddies set in. The animations are available from:

http://www.rsmas.miami.edu/personal/tamay/3D/mlis13.mov and http://www.rsmas.miami.edu/personal/tamay/3D/mlis11.mov 

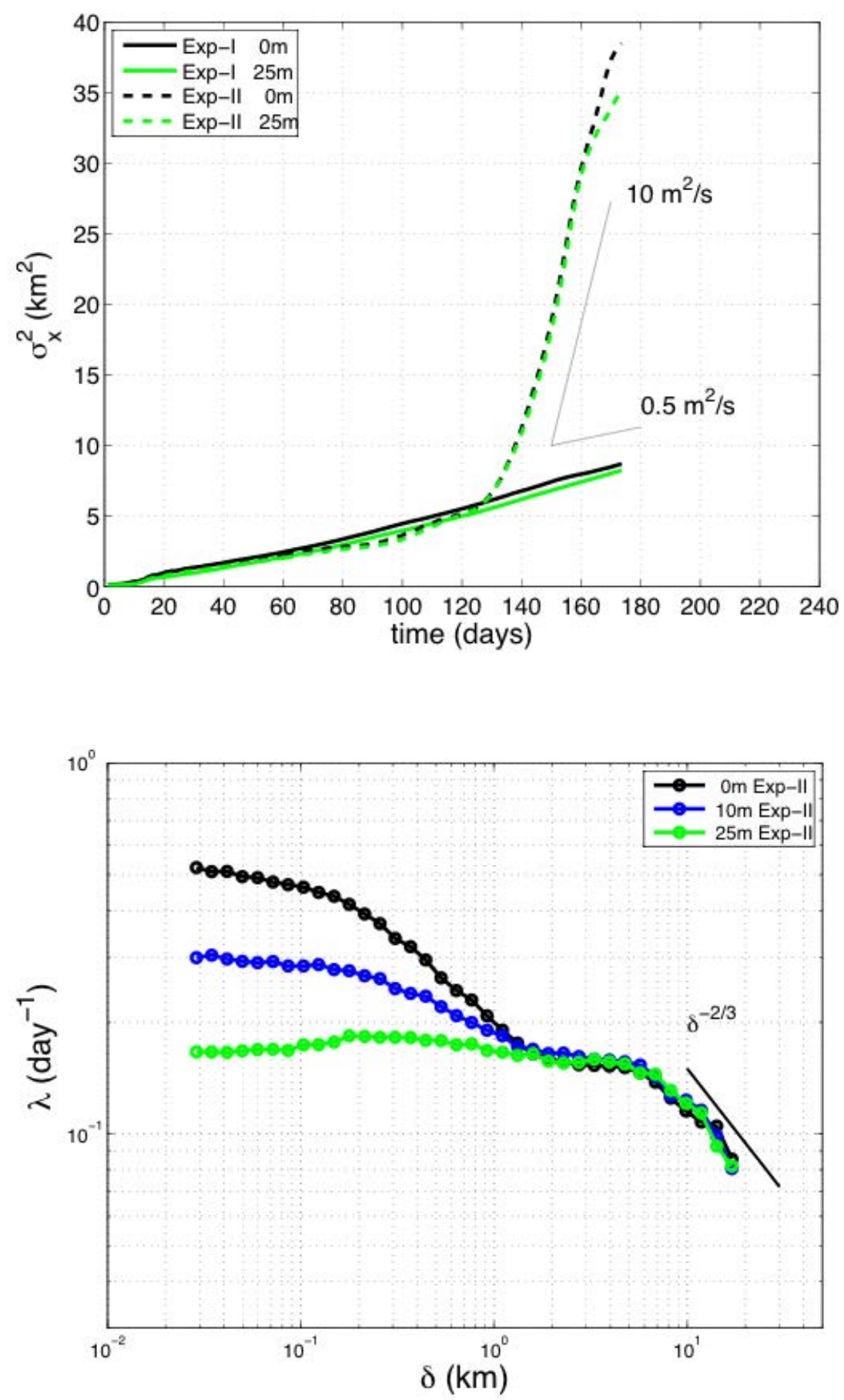

Fig. 3: (Upper panel) Time evolution of the second moment of passive scalar at the surface and at the base of the mixed layer in simulations containing only the MLI (Exp-I, solid lines) and also the deep baroclinic eddies (Exp-II, dashed lines). (Lower panel) Scale-dependent FSLE from particle releases at the surface, middle and base of the mixed layer. Note in Exp-II the the double plateau within the mixed layer, one associated with mesoscale eddies and the other with submesoscale MLI eddies. 
Domain of ROMS

Ocean colour domain (below)

REP10 cluster deployments
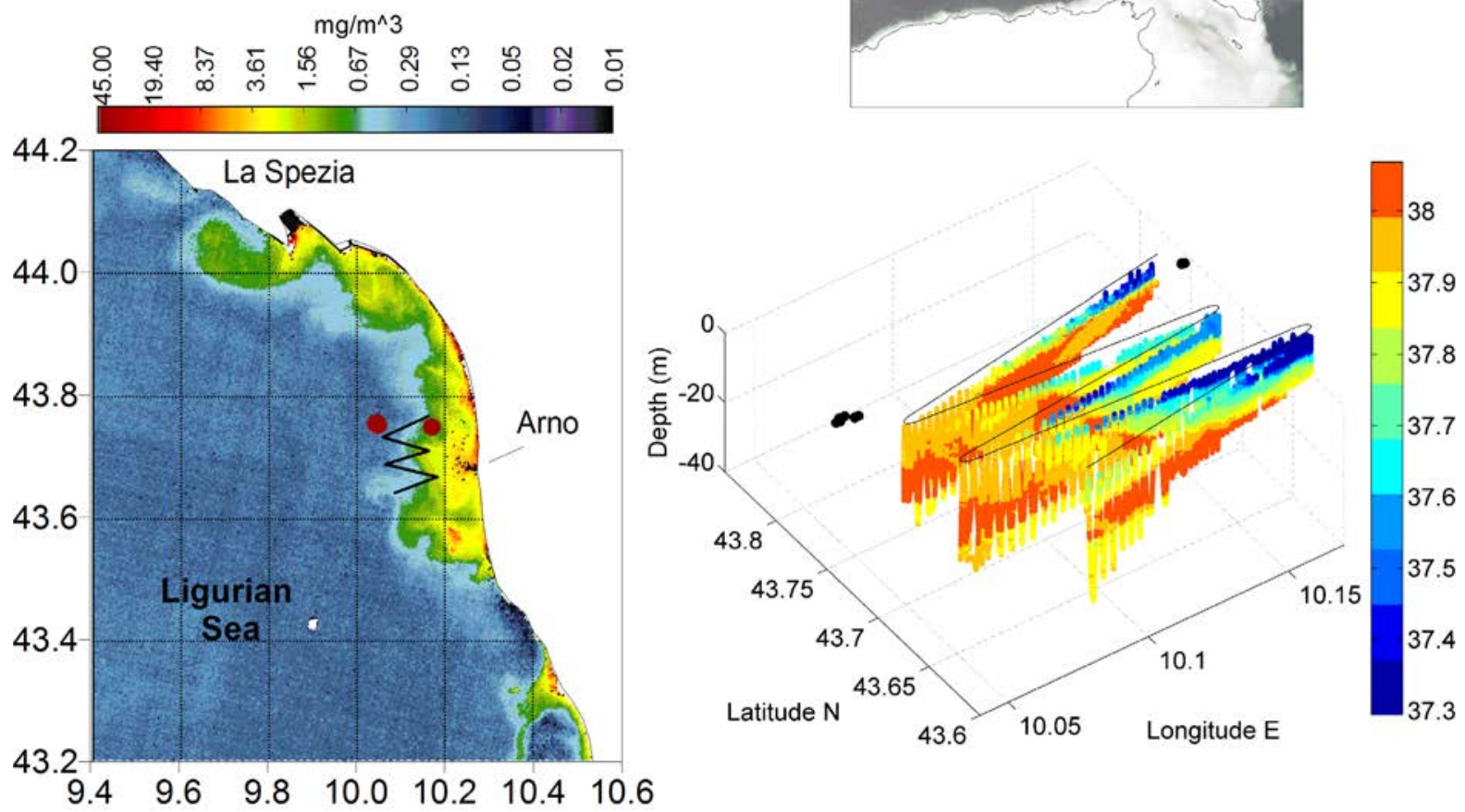

Fig. 4: (Upper right) Region of interest, numerical model domain and and satelitte image frame. (Lower left) Ocean color image (chl1 retrieved from MERIS 09:33 UTC) of 21st August 2010 (before the deployment of the REP10 drifters) with the REP10 cluster deployment positions and the track of the ScanFish MKII used for in situ data collection. (Lower right) Vertical salinity section along the ScanFish MKII track with the REP10 cluster deployment positions across the frontal region. 


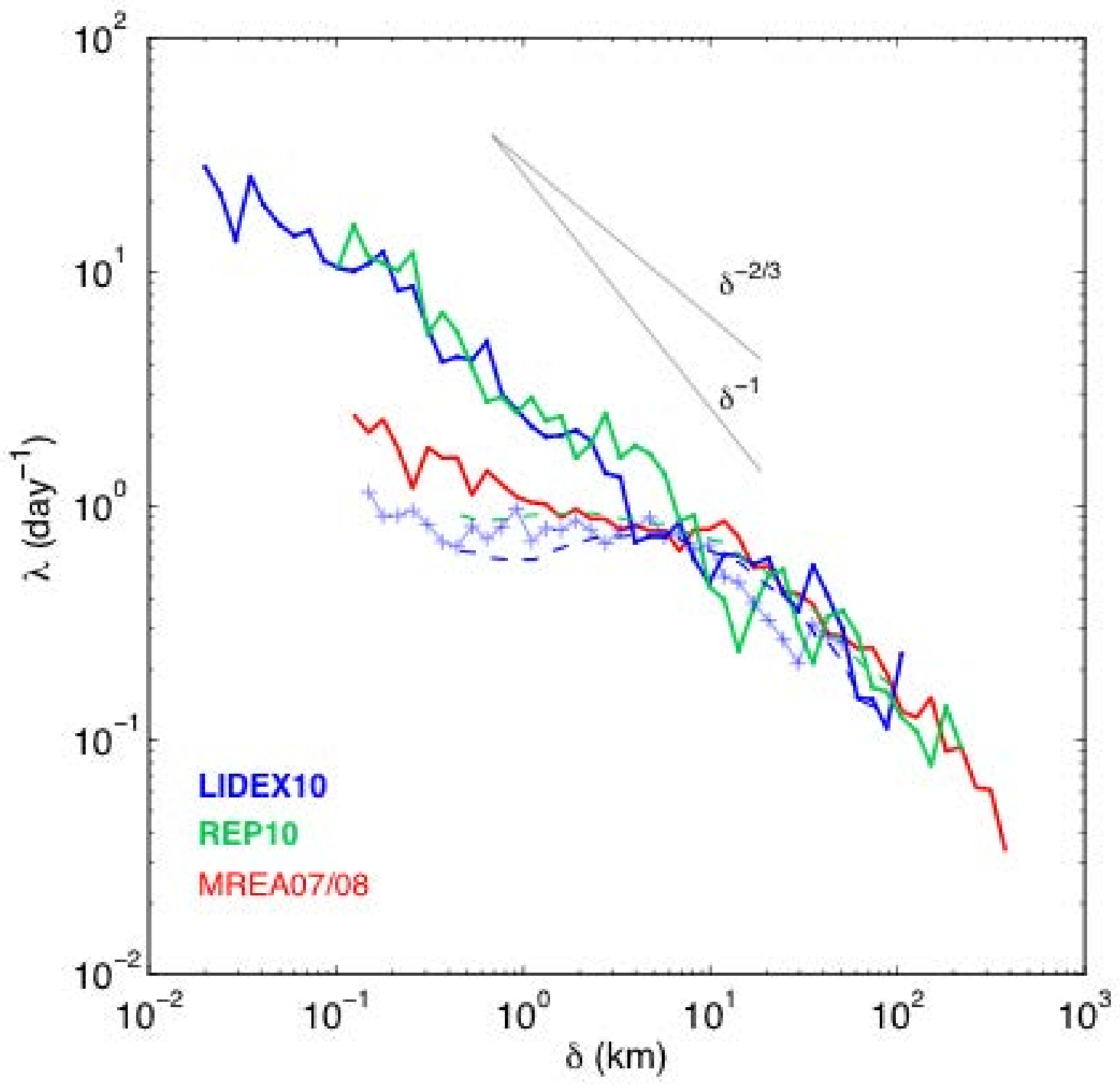

Fig. 5: Scale dependent FSLE for LIDEX10 (solid blue), REP10 (solid green), and MREA07/08 (solid red). Modeling results from synthetic drifters in ROMS simulations are shown as follows: 19 drifters launched as in the LIDEX10 (blue with "+", as in real in-situ experiment), 1485 drifters during LIDEX10 (dashed blue, high number of synthetic drifters in LIDEX10) and 1485 drifters during REP10 (dashed green). Ballistic $\left(\lambda \sim \delta^{-1}\right)$ and Richardson $\left(\lambda \sim \delta^{-2 / 3}\right)$ regimes are indicated. 